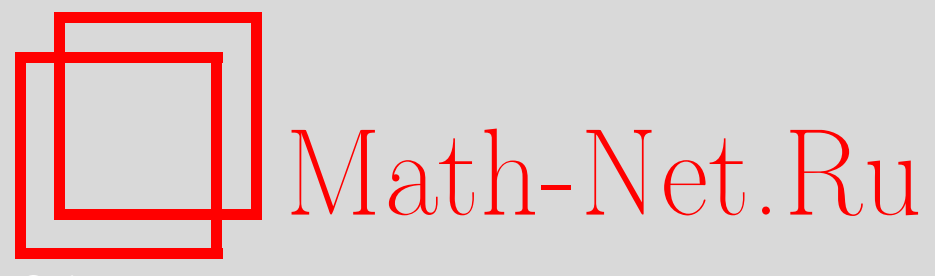

М. Старшов, Где достать поляризованный свет?, Квант, 2021, номер 2, 35-36

DOI: https://doi.org/10.4213/kvant20210205

Использование Общероссийского математического портала Math-Net.Ru подразумевает, что вы прочитали и согласны с пользовательским соглашением http://www.mathnet.ru/rus/agreement

Параметры загрузки:

IP : 18.234 .156 .22

26 апреля 2023 г., 14:35:35

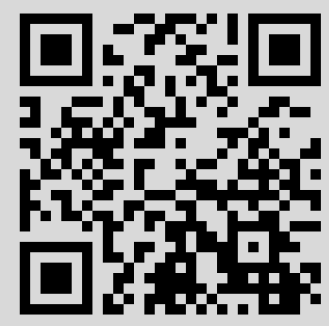




\section{Где достать поляризованный свет?}

M.СТАРШOB

$\mathrm{H}$ ЕДАВНО В ОДНОМ ИЗ МЕТОДИЧЕских физических журналов мне встретилась такая наукообразная фраза: «... весьма непросто создать натурные источники частично поляризованного света». Возможно, натурные источники создавать и не нужно. И не потому, что это непросто, а потому, что они нас окружают постоянно. Известно, например, что поляризованный свет «знают», узнают и используют пчелы. И можно догадаться, что Природа предоставляет им как раз частично поляризованный свет. Гораздо реже можно встретить полностью поляризованный, как говорят оптики, линейно или плоско поляризованный свет. И скорее всего это окажется свет, созданный человеком.

Нельзя не восхищаться призмой Николя, придуманной и изготовленной шотландцем Уильямом Николем в 1828 году. Чтобы сделать это устройство, надо было почти все знать о поляризации света, а главное понимать, что этих приборов хорошо бы иметь два. Тогда можно не только всех убедить, что они работают, но и действительно заставить их работать. Однако ученый изготовил вторую призму, очень похожую на первую, только в 1839 году. Не странно ли?

Итак, призма Николя, или просто николь, из обычного света делает практически полностью поляризованный свет. На нее падает свет с колебаниями в любой плоскости, содержащей направление распространения пучка света, а пропускает она только колебания в одной плоскости, если говорить «на пальцах». Вторая такая же призма может убедить наблюдателя, что из первой свет вышел именно поляризованным.

DOI: https://doi.org/10.4213/kvant20210205
Это красиво и замечательно, только призмы эти делаются из редких, а значит, очень дорогих кристаллов исландского шпата. А вот лет двадцать назад, когда я начинал работать в смене одаренных детей «Созвездие», в отряде юных любителей физики был замечательный мальчик Дима из города Ртищево. На одной из своих лекций я рассказывал о поляризации света, способах получения и применения такого света. Когда лекция закончилась, все мальчишки побежали играть в футбол, а этот Дима пошел по территории детского лагеря, вдоль старых заброшенных корпусов, изредка нагибаясь до земли. Потом отправился к электрику, попросил немного изоляционной ленты, которой он соединил собранные кусочки старого оконного стекла. Было забавно наблюдать, как он предлагал то одному, то другому товарищу посмотреть через его самоделку на небо: «Вот так посмотри, а теперь поверни так! Ну, видишь, как небо меняется?»

Это он сделал так называемую стопу Столетова, которая очень просто и недорого позволяет получить или обнаружить линейно поляризованный свет. И вот, Дима убедился, что небо посылает нам свет в различной степени поляризации в зависимости от положения солнца.

Честно говоря, для такого эксперимента можно вообще ничего не делать руками, достаточно открыть глаза, гуляя по городу или на природе. Вот передо мной здание школы (фото на рисунке 1), но почему такие разные стекла в его окнах: одни какие-то серенькие, а другие совсем черные, как будто и не стекла вовсе? Взглянув с любопытством на похожие окна одного парижского дворца в лучах заходящего солнца, молодой француз Этьен Малюс в начале XIX века и открыл для человечества поляризацию отраженного света.

Блики на воде или на дорогом лимузине и вообще блеск тоже говорят о поляризации отраженного света. Правда, это не касается металлических ручек и других частей машины, «работают» только краска и стекло (с металлами все сложнее). Кто станет физиком или конструктором, возможно, будет этим пользоваться. 


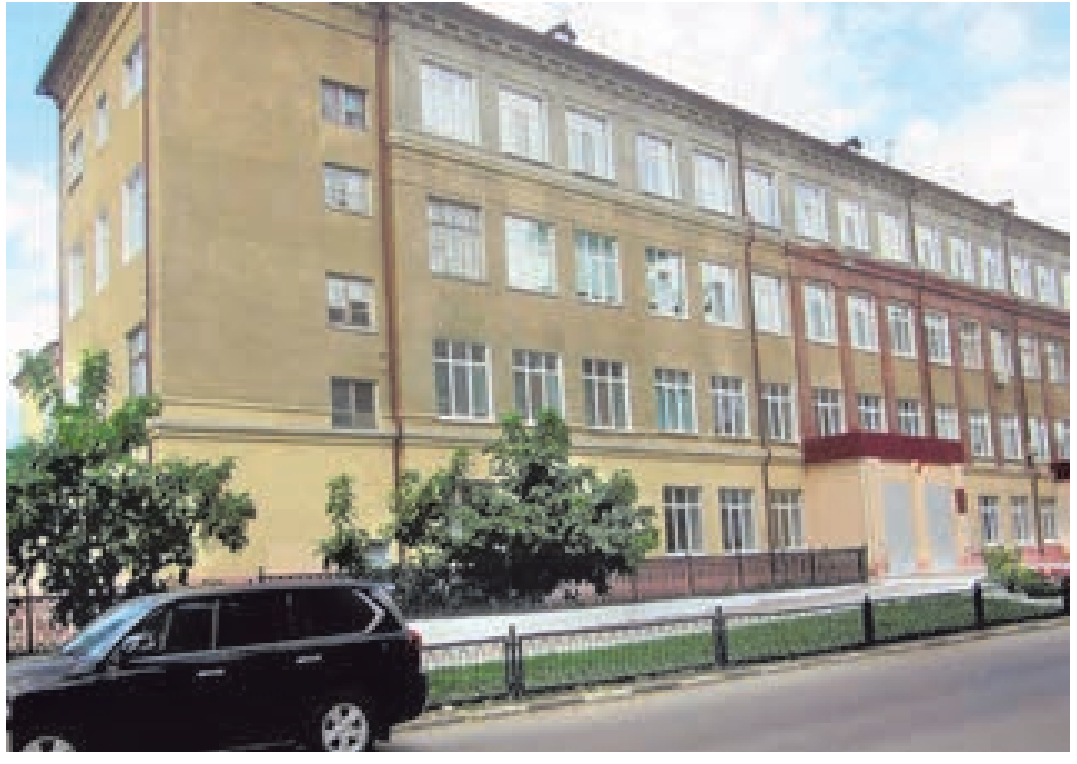

Pnc. 1

С уверенностью процентов на 99 можно утверждать, что среди преданных читателей журнала «Квант» нет ни одного, кто бы не пользовался ежедневно поляризованным светом. Набирая этот текст, останавливаюсь, чтобы исправить ошибку в слове, беру в руки только что сфотографированную стопу Столетова (фото на рисунке 2) и смотрю сквозь нее на экран жидко-кристаллического монитора своего ноутбука. Вижу текст и начинаю поворачивать коробочку вокруг направления на экран. Неожиданно картинка слабеет, мутнеет и темнеет, букв не вижу совсем. При дальнейшем повороте все восстанавливается. Нетрудно догадаться, что от экрана к нам идет поляризованный свет, а стопа это проверяет.

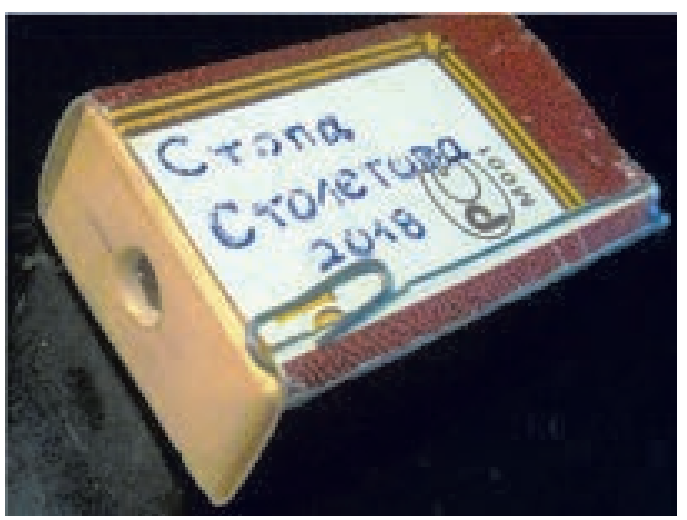

Pnc. 2
Но можно поступить даже проще, достаточно раздобыть кусочек ровного чистого стекла размером в половину тетрадного листа или даже меньше. Держа его сбоку от монитора на уровне глаз, поворачиваю так, чтобы видеть на нем отражение экрана, как в зеркале. Медленно перемещаю руку со стеклом вперед и вверх, не теряя отражение экрана. А изображение вдруг слабеет, почти до исчезновения. Продолжаю движение в том же стиле - изображение снова появляется. И опять пропадает, когда стекло оказывается на уровне экрана и глаз, только с левой моей стороны. Не прикольно ли? Я бы на вашем месте немедленно принялся искать стекло, чтобы проверить прочитанное. Если возьмете зеркало вместо стекла, такого эффекта не получите. Зеркальный слой - это металл, амальгама с высоким коэффициентом отражения, а его защищающее стекло отражает слабо, и глаз изменений не чувствует.

А может быть, куда ни глянь, всюду увидишь частично поляризованный свет? И какие красивые наблюдения можно с ним проводить!

\section{Вниманию наших читателей}

Подписаться на журнал «Квант» можно с любого номера в любом почтовом отделении. Наш подписной индекс в каталоге "Пресса России» - 90964.

Купить журнал “Квант» возможно в магазине "Математическая книга" издательства МЦНМО (адрес интернетмагазина: biblio.mccme.ru), а также в московских книжных магазинах "Библиоглобус», "Молодая гвардия», "Московский дом книги» и в редакции журнала.

Архив вышедших номеров журнала "Квант» имеется на сайте http:// kvant.ras.ru 